\title{
VI. On the semi-arcs of vibration of a clock with a dead beat scapement and deal pendulum
}

\section{Thomas Squire Esq.}

To cite this article: Thomas Squire Esq. (1827) VI. On the semi-arcs of vibration of a clock with a dead beat scapement and deal pendulum, Philosophical Magazine Series 2, 2:7, 34-38, DOI: $10.1080 / 14786442708675615$

To link to this article: http://dx.doi.org/10.1080/14786442708675615

册 Published online: 10 Jul 2009.

Submit your article to this journal

Џ Article views: 2

Q View related articles 두 
34. Mr. Squire on the Semi-arcs of Vibration of a Clock

$p o l$; or $n o p$ is bisected by the line $o l$. In the same way it may be shown that $o n p$ and $n p o$ are bisected by $m n, k p$; and hence the intersection $d$ of these lines is the centre of the circle inscribed in $n \circ p$.

\section{Prop. XIII. (fig. 2.)}

The centre $H$ of the circle circumscribing any triangle $\mathrm{ABC}$ is equidistant from the centre $e$ of the circle $\mathrm{OPZ}$ in : scribed in the triangle, and the centre $d$ of the circle FGE passing through the three centres of the circle of external contact.

For $d$ being the centre of the circle EFG, and $e$ the intersection of the perpendiculars from its angles upon its opposite sides, it follows from Pr. IV. and its corollaries, that if $e d$ is bisected in $H$, the point $H$ is the centre of the circle $A B C$. Whence the proposition is obvious.

Cor.-It is thence also plain that if $\mathrm{ABC}$ be any triangle whatever inscribed in a given circle, the circle through the three centres of the external contact is of an invariable magnitude, viz. having its diameter double of that of the circumscribing circle.

With these remarkable properties of the triangles $\mathrm{ABC}$, EFG, and their respective reciprocals, no $p, k l m$, I shall close the present paper. I intend, however, so soon as I can command sufficient time to arrange my materials, to select from the memoranda which have been accumulating upon my hands for some years, two or three other series of propositions, which 1. flatter myself will not be altogether uninteresting to geometers.

Bath, Jan. 15, 1827.

VI. On the Semi-arcs of Vibration of a Clock with a Dead Beat Scapement and DealPendulum. By Thomas Souire, Esq.*

To the Editors of the Philosophical Magazine and Annals of Gentlemen, Philosophy.

TN a paper dated Dec. 15, 1824, and which appeared in 1 vol. lxv. page 38. of the Philosophical Magazine, I have made mention of having registered several hundred observations of the semi-arcs of vibration of a clock with a dead beat scapement and deal pendulum. Since that time I have considerably extended this series; and from which it appears that these arcs are at times so unaccountably variable, that for this reason I am induced to trouble you with some re-

* Communicated by the Author. 
marks on the subject, hoping at the same time that they may be the means of calling the attention of your readers to this curious circumstance, and which appears to be general in a greater or less degree, under certain atmospheric variations; and is moreover too important to be overlooked, in every case where great accuracy is required.

These variations in the supplementary arc of vibration, are in many cases of much greater consequence to the accurate going of a clock, than theory would seem to point out; and what is worse, perhaps no two clocks can be found, that, under the same circumstances of angular vibration, would have their rates affected in an equal degree; as the thickness and length of the suspension spring, the nature and accuraoy of the scapement, the weight of the pendulum, and the power applied to keep the clock in motion,- - all have a tendency, more or less, to affect the result.

With a given power, weight of pendulum, and dead beat scapement, might not a suspension spring be made of such a length and thickness as perfectly to neutralize the effect on the rate, which would arise from an increase or decrease in the arc of vibration?

Although I have in the paper above alluded to given some account of the clock on which these observations were made, yet perhaps it may not be amiss to say something more in this place respecting it.

This clock has a very perfect dead beat scapement; and the train is of the very best workmanship; the balance-wheel is of brass, and the pallets of steel : there is no jewelling in any part. The pendulum weighs twelve pounds, and is so delicately hung, that a very small maintaining power at the pallets is sufficient to keep it in motion; there are two tangent screws for adjusting the beat, and a graduated nut and index for regulating the rate.

Now from the observations which I have made on the vibrations of the pendulum of this clock, $I$ have found that they are at times regular, or nearly so, for several days together; and on the other hand, they are frequently very irregular, varying several times in the day, and that too, without any apparent cause; but in general I have observed the arcs most variable, when much cirri, cirrostrati, and highly electrified cumuli appear in the atmosphere, and also on the approach of stormy weather; yet this is not always the case, for sometimes the pendulum has a very unsteady motion even in fine and serene weather. I have also found that the same anomaly takes place in clocks with recoiling scapements, and probably in others of the most highly finished workmanship, a circum- 
stance which seems not to have attracted that notice it really deserves.

I will now copy a few observations from my journal; and I may just remark, that in the following table, the hour of the day is according to mean solar time, civil account, and that the thermometer and hygrometer are hung inside the clock-case.

\begin{tabular}{|c|c|c|c|c|c|c|c|}
\hline \multicolumn{8}{|c|}{ Table of Semi-arcs of Vibration, \&c. Power $3 \frac{1}{2}$ lbs. } \\
\hline $\begin{array}{l}\text { onth and } \\
\text { Day. }\end{array}$ & \multicolumn{2}{|c|}{ Hour. } & & & 苞 & 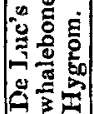 & State of the Weather. \\
\hline \multirow[t]{37}{*}{ Sept. 17.} & & $20^{1}$ & $2^{\circ}$ & $8^{\prime}$ & 60 & 61 & \multirow{11}{*}{$\begin{array}{l}\text { Bright, yet sultry, } \\
\text { max. temp. of exter- } \\
\text { ternal air 70 . Bar. } \\
\text { sinking, wind E. } \\
\text { - and n. } \\
\text { Showery, wind N.E. } \\
\text { and rather brisk. } \\
\text { Heavy rain at night. }\end{array}$} \\
\hline & 9 & 35 & & 0 & 60 & $6 i$ & \\
\hline & 11 & $\mathbf{0}$ & & 3 & 62 & 61 & \\
\hline & 14 & 45 & & $\mathfrak{l}$ & 67 & 60 & \\
\hline & 1.9 & 35 & & 6 & 67 & 61 & \\
\hline & & 20 & 2 & 5 & 64 & 61 & \\
\hline & 12 & 0 & 2 & 9 & 65 & 61 & \\
\hline & 13 & $\mathbf{0}$ & 2 & 3 & 65 & 61 & \\
\hline & 14 & 0 & & 58 & 65 & 62 & \\
\hline & 17 & 0 & 2 & 5 & 65 & 62 & \\
\hline & 21 & 45 & 2 & 8 & 65 & 62 & \\
\hline & & 30 & 2 & 11 & 64 & 62 & \multirow{3}{*}{$\begin{array}{l}\text { Fair, bright \& warm, } \\
\text { max. temp. } 69^{\circ} .\end{array}$} \\
\hline & 20 & $\mathbf{0}$ & 2 & 6 & 69 & 62 & \\
\hline & 8 & 16 & 2 & 9 & 66 & 62 & \\
\hline & 11 & 0 & 21 & 11 & 66 & 62 & \multirow{3}{*}{$\begin{array}{l}\text { Rain A.M., afterwards } \\
\text { fair and windy. }\end{array}$} \\
\hline & 14 & 15 & 2 & 16 & 66 & 62 & \\
\hline & 21 & 15 & 2 & 18 & 66 & 62 & \\
\hline & 7 & 35 & 2 & 10 & 61 & 62 & \multirow{4}{*}{$\begin{array}{l}\text { Fair, and mostly } \\
\text { bright. }\end{array}$} \\
\hline & 12 & 0 & 2 & 13 & 61 & 61 & \\
\hline & 14 & 10 & 2 & 10 & 63 & 62 & \\
\hline & 21 & 0 & 2 & 0 & 61 & 61 & \\
\hline & 8 & $\mathbf{0}$ & & 15 & 56 & 61 & \multirow{4}{*}{$\begin{array}{l}\text { A cloudless sky, some } \\
\text { wind middle of the } \\
\text { day. }\end{array}$} \\
\hline & 11 & 36 & 2 & 18 & 58 & 61 & \\
\hline & 15 & 0 & 2 & 12 & 69 & 61 & \\
\hline & 20 & 25 & 2 & 1 & 61 & 61 & \\
\hline & & 0 & 2 & 7 & 56 & 61 & \multirow{2}{*}{$\begin{array}{l}\text { Fair, with drying } \\
\text { winds. }\end{array}$} \\
\hline & 21 & 0 & 2 & 5 & 61 & 61 & \\
\hline & 8 & 10 & 2 & 2 & 59 & 61 & \multirow{6}{*}{$\begin{array}{l}\text { Early A.M. dark } \\
\text { rain middle of the day; } \\
\text { dark } \cap \text { W. with lights } \\
\text { and distant thunder. } \\
\text { Mostly fair. }\end{array}$} \\
\hline & 6 & 35 & 2 & 13 & 63 & 61 & \\
\hline & 19 & ) & 1 & 57 & 63 & 61 & \\
\hline & 20 & 35 & 2 & 0 & 62 & 61 & \\
\hline & 7 & 45 & 2 & 4 & 61 & 62 & \\
\hline & & 0 & $z^{2}$ & 11 & 67 & 62 & \\
\hline & 9 & 15 & 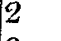 & 4 & 64 & 64 & \multirow{4}{*}{$\begin{array}{l}\text { Some rain early A.M. } \\
\text { afterwards fair and } \\
\text { mostly bright. }\end{array}$} \\
\hline & 2 & 0 & 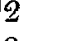 & 7 & 66 & 62 & \\
\hline & 7 & 10 & 2 & 4 & 68 & 62 & \\
\hline & 0 & 20 & 2 & 8 & 67 & 62 & \\
\hline
\end{tabular}


I shall now advert to the valuable series of observations made by Col. Beaufoy in $1819,1820,1821$ and part of 1822 , on the going of a clock with a straight-grained deal pendulum rod. From these observations I am led to believe that the small and sudden irregularities in the rate of this clock are not referable to changes in the length of the pendulum, but to those in the arc of vibration : for had the changes of the atmosphere affected the length of the pendulum, whilst the arc of vibration remained constant, the clock would have gradually gained upon its mean rate as the summer advanced, and lost as the winter approached, which does not seem to have been the case from these observations. So that we may conclude this pendulum rod to have undergone little or no change during the period of three years and upwards that the daily rate of this clock was registered.

But if we take the differences of each succeeding daily rate, as given in the tables for the deal pendulum, and compare them with like differences of the daily rate, as found by a subsequent series of observations made also by Col. Beaufoy in 1824 and 1825, with a teak pendulum, we shall find that in the latter year, though the clock gradually gained from the beginning of March, when its daily rate was about two seconds, to the 6th of August, when its daily rate was 9.5 seconds; yet the maximum difference of the rates with the teak pendulum, only exceeded that of the deal pendulum 31 of a second.

From the great increase of the daily rate (as observed above) during the spring and summer months, we must infer that there was a contraction of the teak pendulum, and which came to its maximum about the beginning of August: nevertheless the rate was not much affected by this cause, from day to day, as the second differences are not found to be more dissimilar than those obtained from the observations made with the deal pendulum.

As it is possible to render the deal pendulum perfectly constant under all changes of the atmosphere,-which is all that is wanted in this respect, for the purpose of accuracy ; it is therefore unnecessary to have recourse to the more expensive mode of compensation, which from the uncertainty in the ratio of expansion of the different metals of which the gridiron and similar pendulums are composed, together with the nicety required in the adjustment of the different parts, so as to insure a perfect balancing of effects in the centre of oscillation, must be a work that requires more time and attention for insuring a requisite degree of accuracy than is usually bestowed on such occasions: whilst after all, if the arc of vibration be in a state of fluctuation, a doubt may arise whether to ascribe 
the variation in the rate to this cause, or an imperfect compensation. Since (as has been observed before) a pendulum of deal may be made constant under all the vicissitudes. of the seasons, there is therefore nothing remaining but to render the arc of vibration also constant, with a given maintaining power in all cases of atmospheric influence; and then we shall be able to give to that useful machine the clock, that equable motion which constitutes its intrinsic value, for measuring time with accuracy.

Epping, Dec. 14th, 1826.

I remain, Gentlemen, most respectfully yours, Thomas Squire.

\section{On Mechanical Science.*}

I' $\mathrm{T}$ is a very common opinion that there is an essential diffe1 rence between the principles of Geometrical and of Mechanical science. The former is supposed to be independent of matter, the latter to be entirely dependent on it. Geometrical science is imagined to be derived without aid from experience, while mechanical science is said to be founded wholly on observation and experiment. These notions appear to have had much influence in retarding the progress of pure science, by limiting its extent, and causing the important doctrines of mechanics to be mixed with matters of mere observation; that is, instead of a general and unlimited investigation of the relations that might exist among forces, times, and spaces, it is confined to those relations only which are observed to take place in the ordinary natural phenomena; a few cases excepted, which are evidences of the general nature of the science.

In no instance have I seen a more distinct announcement of this narrow opinion regarding mechanics than in the excellent discourse which commences the "Library of Useful Knowledge" now publishing for the diffusion of science, and having an equal feeling of interest for the progress of pure and of practical science. I shall not scruple attempting to show that those opinions, which are not peculiar to that work, are not perfectly correct.

It will be admitted that an idea of a third dimension is necessary to geometry. Now I contend that the mind cannot obtain this idea without a previous one of power; and that it is simply power acting unresisted, which gives us our knowledge of space as being bounded by a figure of three dimensions. Deprive the mind of the aid of power, and it must become wholly incapable of conceiving the idea of space, or figure of three dimensions; for the organ of sight gives no

* Communicated by the Author. 